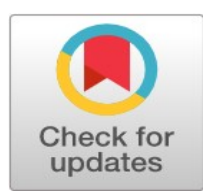

\title{
Using open innovation model to enhance knowledge sharing in Vietnam University
}

\author{
Tang Due $\mathrm{Au}^{*}$
}

Department of Business Administration Asia University, Taichung, Taiwan

\author{
Index Terms \\ Open innovation \\ Knowledge sharing \\ Channel \\ Linkage \\ University
}

Received: 10 June 2016

Accepted: 17 September 2016

Published: 27 October 2016

\begin{abstract}
Enterprises today are embracing ways of doing business to adapt to a knowledge-based economy effectively. The adoption of Open Innovation (OI) has been one of the most appropriate ways to absorb both internal and external potential ideas. Meanwhile, education reform is an urgent need as Vietnam universities have focused on shifting from term-based training to a credit-based system as well as moving towards research-intensive universities. The sharing of knowledge among academic communities (learners, teachers, university managers) and external communities (enterprises) can contribute to this shift. The issue of how to establish a barrier-free environment for knowledge flows is a requirement. Based on literature review and quantitative research at the University of Foreign Language Studies (UFLS), University of Danang (UD), Vietnam, the paper aims to point out important roles played by various communities and proposes some possible channels through which the sharing of knowledge flows has taken place in a university context. This paper also develops a conceptual model for understanding knowledge sharing in three main linkages: lecturer-student, lecturer - lecturer and university - enterprise linkage through the lens of OI. This paper concludes with a discussion of recommendations to enhance knowledge sharing in the three above-mentioned linkages.
\end{abstract}

(C) 2016 The Author(s). Published by TAF Publishing.

\section{INTRODUCTION}

In knowledge-based economy, enterprises are motivated to renew their business models to absorb innovative ideas. One century ago, most of innovative ideas were brought about by innovative individuals, imitators or Research and Development (R\&D) departments of large-scale companies (Chesbrough, 2006). In the present, however, innovative ideas come from different sources, including customer, supplier, government, competitor and academic institute. A new business model with few boundaries and more linkages is an urgent need. Chesbrough (2006) introduced a new term of business model "Open Innovation" satisfied to meet these demands. The term "Open Innovation" is described as a model in which both internal and external sources including technology, knowledge and process get involved into the processes of creating and commercializing new products, services or processes (Chesbrough, 2006). OI has two main dimensions including inbound and outbound OI dimensions. Inbound OI refers to the transfer and use of external sources into the firm, whereas outbound OI refers to the transfer of internal sources to outside businesses (Chesbrough \& Crowther, 2006). OI model provides open business communities with as many as opportunities to share and develop their initiatives. OI encourages firms to search for appropriate outside partners and take advantage of strengths available in surrounding business rather than relying on inside sources. University plays a major role in the knowledge-based economy. University

\footnotetext{
${ }^{*}$ Corresponding author: Tang Due Au

†Email: tdau@ufl.udn.vn
} 
is one of the richest knowledge sources. Academic communities including researchers, lecturers and students are regarded as the main provider of knowledge, talent and innovative ideas. The reason is that university is portrayed as a motherland of technological innovations and technologies that are engines of economic development as well infrastructure foundation for innovation (Richard, 1999). The interdependence of university with the local, regional, and global communities is emphasized as one of the most critical aspects in creating sustainable future (Cortese, 2003).

University should promote a culture in which business and academic activities can connect and flourish (Youtie \& Shapira, 2008, cited in Johnston, Robinson \& Lockett, 2010). The role of university should not be limited to teachinglearning activities. Academics should participate in activities in regard to research and economics. However, most OI studies have been focused on the business context. Few studies on OI were conducted within academic contexts. Padilla-Meléndez \& Garrido-Moreno (2012) conducted an investigation on 382 senior researchers at Spanish universities in order to examine factors influencing researcher engagement in knowledge transfer and exchange in an OI context. More studies on OI activities and knowledge sharing in different organizational contexts should be taken into consideration (Perkmann \& Walsh, 2007).

Knowledge-intensive organizations including university or research institute play an essential role as a part in OI model. Academic communities play as key agents in university. People with different personal profiles, expectations from and mutual trusts with their partners determine their knowledge sharing processes (Padilla-Meléndez \& Garrido-Moreno, 2012; Cheng, Ho \& Lau, 2009; Zaqout \& Abbas, 2012; Chmielecki, 2013). The variety of social processes can lead to either success or failure of knowledge transfer and exchange in an OI context (Johnston, et al., 2010). Universities, therefore, need to review different types of relationship they have in an OI context. The sharing of knowledge between and among communities in an OI context needs more investigations. More specific studies examining knowledge sharing in different linkages, such as lecturer - student, university - lecturer and university enterprise linkage should be paid attention.

This paper aims to fill these research gaps by presenting research-based solutions to enhance the sharing of knowledge between and among academic communities in an OI context. The study also develops a conceptual model pointing out channels through which knowledge sharing was conducted by various communities as implementing OI model in Vietnam universities.

\section{LITERAT URE REVIEW}

\section{Open Innovation and University}

The success of OI activities in enterprises is associated with the participation of various organizations. Among these organizations, universities play an essential role in OI model because they are main sources of knowledge. Enterprises collaborate with universities for various reasons. Firms are expected to be given opportunities to access knowledge transfer and innovative knowledge flows from local higher education institutes (Fukugawa, 2006). The enterprises' motives for engaging in university-industry relationships may be classified into two categories including generic and commercial benefits. Many studies found that university cooperates with industry for commercial benefits. University is one of the most important collaborative partners with enterprises in terms of innovative activities and outcomes (Perkmann \& Walsh, 2007; Howells, Ramlogan \& Cheng, 2012). Small and medium-sized enterprises build partnership with universities and research institutes for strategic alliances and fundamental research (Lee, Park, Yo on \& Park, 2010).

Among newly Science and Technology Basic Law (STBL) enacted countries, Taiwan is the most enthusiastic generator of university patents and licensing income (Chang, Chen, Hua \& Yang, 2005). The number of education \& training cases and collaborative projects between industry and academic field increased by 19.5 and 8.1 percent respectively from 1997 to 2001 in Taiwan. Industrial contract research projects and research consortia grew 3.2 and 1.9 percent, respectively. The increase in generic benefits motivates firms to interact with university. University-industry linkage allows firms to get access to skilled students and emerging technologies to enhance their knowledge base (Dritsas, Kaloghirou \& Cokkinos, 2001 Perkmann \& Walsh, 2007). Moreover, employing skilled students as well as supporting for master's and doctoral theses would be of great interest for firms that need to specify university knowledge to be able to absorb it in their products, processes, and organization (Bekkers \& Freitas, 2008).

There are different mechanisms through which knowledge and innovative idea flows are transferred, exchanged or co-produced between universities and enterprises. Mechanisms were categorized by the degree of formalization of interaction (formal and informal channels); the type knowledge transferred (tacit knowledge and non-tacit knowledge channels) and the intensity of personal relations 
(personal and non-personal channels) (Schartinger, Rammer, Fischer \& Fröhlich, 2002). Perkmann \& Walsh (2007) classified seven university-industry links including formal mechanisms (research partnerships, research services, mobility of researchers, commercialization of property rights, academic entrepreneurship) and informal ones (informal interaction, scientific publications).

D'Este \& Patel (2007) showed a variety of channels including formal channels (consultancy and contract research, joint research, training) and informal channels (meetings, conferences, and the creation of new physical facilities). According to an investigation conducted on enterprises in Vietnam, Tran \& Kocaoglu (2009) proposed three main ways of technology transfer, including formal mechanisms (academic-industry cooperation, technology patent transfer) and informal ones (the formation of new firms by university members (spin-off companies).

\section{Knowledge Sharing in University}

Career development is a better career plan as revealed by Handoko (2008:123) that career University is portrayed as a knowledge-intensive environment in the world. Knowledge sharing is a foundation for the success of knowledgeintensive environment. The studies on knowledge-sharing in university have attracted more attention. There are several empirical studies concerning to find out factors influencing knowledge sharing process (Zaqout \& Abbas, 2012; Wei Chong, Yen Yuen \& Chew Gan, 2014; Pham, Nguyen \& Nguyen, 2015). Zaqout \& Abbas (2012) examined the knowledge sharing among 245 graduate students at Malaysian Universities and found that mutual trust with colleagues and supervisors, social networks and information communication technology significantly stimulate both tacit and explicit knowledge sharing.

Another investigation conducted in Malaysian universities found that reward, fair performance appraisal, recognition, publication of knowledge and the application of technology tools positively related to the sharing of knowledge (Wei Chong et al., 2014). Based on a sample of 230 academics in UK Universities, Fullwood, Rowley \& Delbridge (2013) found that relationship improvement with colleagues, internal promotion opportunities and external appointment can stimulate knowledge sharing. According to a recent investigation on 123 lecturers and staffs in 10 Vietnam universities, the research results presented that job demands, training \& development and technology support are main factors influencing knowledge sharing behaviors (Pham et al., 2015).
As can be seen from above studies on knowledge sharing in university, the research targets mainly focused on exploring barriers that influence the sharing of knowledge in the whole university context. However, university is a knowledge-based environment in which a series of partners can share their common interests for different purposes. Partners in a university context are divided in two categories including (1) academic communities including lecturers, students, university leaders (2) external communities including entrepreneurs, parents, local and regional communities, education funders, governmental agencies, alumni or accreditation organizations.

Barriers regard to individual aspects including trust, time, age and gender that are the most important ones (Chmielecki, 2013). Each actor has different individual characteristics. It makes sense that each participant in knowledge sharing processes has different motivations. Studies about knowledge sharing on different groups are needed to draw a better comprehensive picture on knowledge sharing in a university context.

\section{APPLICATION OF OI MODEL TO ENHANCE KNOWLEDGE SHARING IN VIETNAM UNIVERSITY}

The research aims to find out main linkages in knowledge sharing and explore effective knowledge-sharing channels through which these linkages can stimulate the effectiveness of knowledge sharing processes. An investigation was conducted on UFLS's lecturers and researchers. UFLS is one of the seven member universities and colleges of The UD. Developing UFLS into a Research-Oriented University by 2020 has become the determination and strong will of UFLS's academics.

Lecturers were research participants because of two main reasons, (1) they are those who directly interact with other open communities, (2) they are only those who can take in charge of two roles including teaching and managers in UFLS. Lecturers are adequate factors in conducting teaching - researching activities with students and other academics and in building partnerships with entrepreneurs. The main aim of this study was to develop a conceptual framework to promote knowledge sharing through different linkages via the lens of OI model. The following research questions were thus proposed:

(1) Which linkages are the most important in knowledge sharing processes?

(2) What are the main knowledge sharing channels in each linkage? 


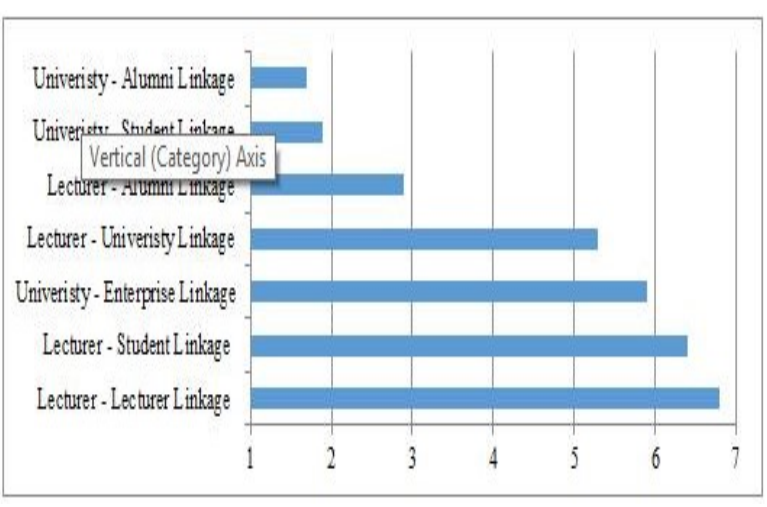

FIGURE 1. The importance degree of linkages in knowledge sharing process

Questionnaires were sent to 100 full-time lecturers at UFLS. A total of 80 questionnaires were collected, which contribute to a response rate of $80 \%$. Participants were asked to rate the importance of each linkage. Each item was measured by the 7-point Likert scale, ranging from (1) the lowest importance to (7) the highest importance. The ranking of linkages is provided in Figure 1.

Participants were asked to identify three most important knowledge-transfer channels in each linkage. A conceptual model, based on the research results, was proposed (Figure 2).In the light of the above-mentioned aspects, a number of solutions in regard to lecturer, manager, student and enterprise need to be fully attended to enhance knowledge sharing in Vietnam universities.

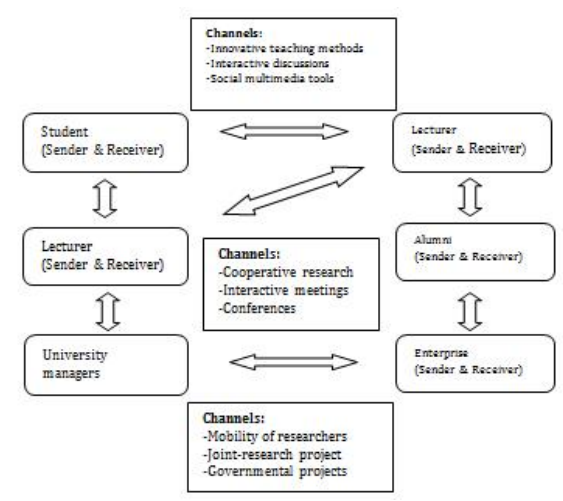

FIGURE 2. Knowledge sharing model in an OI context

Knowledge Sharing Amongst Lecturers in an OI context Colleague is rated as the most important partner with lecturers in knowledge sharing processes. This finding is obvious because lecturers are considered researchers who participate in all knowledge transfer exchange processes including scientific discovery, securing and marketing in tellectual property and gaining profit (Padilla-Meléndez \& Garrido-Moreno, 2012). University researchers also have higher important contributions to all knowledge transfer channels than industrial researchers have (Bekkers \& Freitas, 2008). Three best ratings of knowledge-transfer channels include (1) cooperative research, (2) interactive meeting and (3) conference. Cooperative environment is a foundation for effective exchanges of knowledge flows amongst academic staffs. Research findings show that even ideas of research can be discussed among colleagues through faceto-face meetings or conferences. Knowledge and experience of colleagues can address limitations existing in research processes and open new research directions for further studies. Knowledge sharing amongst academic staffs, however, is significantly affected by personal expectation and incentive system (Cheng, et al., 2009) along with mutual trust (Chmielecki, 2013; Wei Chong et al., 2014). Thus, interactive meetings and conferences are effective channels in which lecturers have more opportunities to find partners who share the same research interests.

\section{Knowledge Sharing Between Lecturer and Student in an $\mathrm{OI}$ context}

Students are the second most effective partners with lecturers' knowledge sharing activities. The role of student becomes more important when universities move from term-based training to credit-based system. Student-based learning situates the learners as the primarily active role in knowledge sharing because students are those who are decision makers in learning processes. Interactive lessons and face-to-face discussions are rated as two best effective channels in knowledge sharing in lecturer-student linkage. This recommendation is consistent with Pan \& Leidner (2003) who claimed that knowledge expands are considerably associated with social and community interactions (cited in Cheng et al., 2009). Högberg \& Edvinsson (1998) also pointed out that knowledge sharing amongst higher-education students should be active and collaborative through answering questions, solving problems, learning new concepts, enhancing students' understanding of a particular subject, and helping others (cited in Zaqout \& Abbas, 2012). Interaction plays a vital role in knowledge sharing among students (Ma \& Yuen, 2011). More importantly, knowledge creation from learners can be conducted via their interactions and discussions with those who are more knowledgeable Vygotsky, 1978, cited in Zaqout \& Abbas, 2012). Thus, lecturers serve as inspirers in stimulating knowledge creation of and knowledge shar- 
ing among learners. Lecturers should motivate students to share their enthusiasm through interactive lessons in association with experiences of scientific research. The questions provided by lecturers in the processes of knowledge sharing can widen and deepen theory-based knowledge of students. To achieve this, lecturers should upgrade upto-date knowledge through their scientific research activities. Each lecturer should determine main research fields and link the research's latest knowledge to lessons. One of the main goals in the teaching processes is to guide students into making new interpretations and new ideas from supplied lessons. This study also showed technological barriers were more underestimated than individual ones. The application of social information network occupied the third place. This finding is consistent with that of Jer Yuen \& Shaheen Majid (2007), who demonstrated that face-to-face communication channels were more preferred by students in Singapore universities than multimedia channels such as chat, email and telephone. One of the reasons may be that information communication technology only allows the sharing of explicit knowledge (one that is easy to be calculated or communicated, such as training manuals, written working procedures etc.), not tacit knowledge (ones that are developed through experience and practice, such as skills, know-how etc.) in student - lecturer linkage (Zaqout \& Abbas, 2012).

\section{Knowledge Sharing Between University and Enterprise in an $0 I$ context}

Enterprises are considered the most important partner who helps to bring academic research results into commercialized products. The training programs and jointventure research stand out as two primary mechanisms in industry - university collaboration. These findings are in the line of previous studies, for example Fukugawa (2006), who found that new-technology based firms in Japan work with local higher education institutes as research partners via joint research and Howells et al., (2012), who showed that training and continuing professional development is ranked number one among key mechanisms in industry - university collaborations. Padilla-Meléndez \& GarridoMoreno (2012)also pointed out social network factors including conjoint research and interactions with researchers of private companies that are the most important ones for researcher involvement in knowledge sharing between companies and universities in an OI context. In term of training programs, enterprises employ university-based research teams as parts in their Research \& Development
(R\&D) activities. Conversely, senior employees of R\&D department can work as lab-assistants with university professionals. The ultimate goal is to make experienced R\&D staff who can conduct their own R\&D activities. Universities can help enterprises develop technological base and provide them with professionals whose research interests suit businesses' development directions. Enterprises must stand side by side with the universities in scientific research activities and projects through financial supports and technological contributions. The research findings of Bekkers \& Freitas (2008) showed that employing skilled students and offering supports for Master's and Ph.D. theses can allow enterprises to specify university knowledge to be able to absorb it in their products, processes and organization. In term of joint-venture research, the mutual-beneficial relationship between university and enterprise should be clearly identified. Enterprises should clearly state the contents of the research, the co-participants as well as the financial support. Enterprises also provide university with capital base and techniques that support the success of research, as well as offer opportunities that allow research results to be commercially implemented. Universities are given opportunities for access to supporting funds and potential markets from their partners. Universities increase their financial resources by selling their intellectual properties like patents, copyrights to entrepreneurs as well as introducing new products to potential markets.

Although government projects are rated less important channels than research training and conjoint research, it is obvious that government is one of the most important keys in enhancing the interaction between university and industry. Government is one of the most important network intermediaries who may have enough institutional authority and industry experience to drive through knowledge transfer exchange between academics and businesses (Johnston, et al., 2010). Research relevance and lack of information from university partner are portrayed as two significant barriers for firms interacting with academics (Howell, et al., 2012). Therefore, government played a vital role in reviewing as well as removing unnecessary barriers in regard to knowledge exchange between university and industry. State can help connect the demand-side including start-ups and entrepreneurs with the supply-side including universities and R\&D centers. For example, state establishes consulting offices which provide enterprises with different service packages. These offices help research demands of each enterprise to be sent to the right research institutes. The participation of university researchers and 
entrepreneurs in national conferences can stimulate their interaction channels.

\section{CONCLUSION AND IMPLICATIONS}

The main contribution of this paper is to propose a framework presenting main linkages as well as possible channels for knowledge-sharing processes of each linkage in an OI context. This study has a number of limitations. First, the sample size was small and the database was obtained from only one university. Thus, the research results cannot be effectively applied to other universities. Second, this study does not investigate the relationship between OI model and knowledge sharing activities. It is limited to confirm that OI model, in comparison with other models, provides more advantages for knowledge providers or receivers. However, the paper can open up new directions of research on OI and knowledge sharing in the context of university.

First, this paper becomes a potential reference for future research because the study, in some extent, solves two research limitations on knowledge sharing, including (1) a better understanding on knowledge sharing in an integrated network rather than dyadic interactions; (2) a difference between face-to-face knowledge sharing communities and knowledge sharing via electronic knowledge system (Wang \& Noe, 2010). Second, more specific investigations on the relationship among types of transferred knowledge, types of knowledge sharing channels and characteristics of actors involved in knowledge sharing processes should be further studied. The relationship among the characteristics of knowledge, the characteristics of knowledge providers or users, and the environment in which knowledge is produced and used is linked with the knowledge transfer channels (Bekkers \& Freitas, 2008).

Future research could address how the adoption of OI activities affects upon the knowledge sharing degrees among various channels of knowledge transfer. Understanding the association between $\mathrm{OI}$ activities and degrees of knowledge sharing through various channels is able to provide stronger foundations for policy implementations aiming to enhance the knowledge flows among academic actors. In addition, the separation of knowledge characteristics into explicit and tacit knowledge can be further studied to find out more specific knowledge sharing networks. The paper, however, demonstrates the possibility of adoption of an innovative business model - OI into Vietnamese universities.The research findings can help educators to propose effective solutions and long-term plans to create an innovative academic environment. An environment which promotes the interaction among employees effectively facilitates the ability of knowledge sharing (Dewey, 2005, cited in Wang \& Noe, 2010). The strong relationship between internal and external stakeholders is emphasized in OI model. Some solutions are also proposed to strengthen the involvement of partners in the establishment of an innovative academic environment.

\section{REFERENCES}

Bekkers, R., \& Freitas, I.M.B. 2008. Analysing knowledge transfer channels between universities and industry: To what degree do sectors also matter? Research Policy, 37(10): 1837-1853. DOI: 10.1016/j.respol.2008.07.007

Chang, Y.C., Chen, M.H., Hua, M., \& Yang, P.Y. 2005. Industrializing academic knowledge in Taiwan. Research-Technology Management, 48(4): 45-50.

Cheng, M.Y., Ho, J.S.Y., \& Lau, P. M. 2009. Knowledge sharing in academic institutions: A study of Multimedia University Malaysia. Electronic Journal of Knowledge Management, 7(3): 313-324.

Chesbrough, H.W. 2006. Open innovation: The new imperative for creating and profiting from technology. Boston, MA: Harvard Business Press.

Chesbrough, H., \& Crowther, A.K. 2006. Beyond high tech: Early adopters of open innovation in other industries. R\&d Man- $\quad$ agement, 36(3): 229-236. DOI: 10.1111/j.1467-9310.2006.00428.x7

Chmielecki, M. 2013. Knowledge sharing among faculty-qualitative research findings from Polish Universities. Interna- tional Journal of Contemporary Management, 12 (3): 92-102.

Cortese, A.D. 2003. The critical role of higher education in creating a sustainable future. Planning for Higher Education, 31(3): 15-22.

D’Este, P. \& Patel, P. 2007. University-industry linkages in the UK: What are the factors underlying the variety of interac- $\quad$ tions with industry? Research Policy, 36(9): 295-1313. D0I: 10.1016/j.respol.2007.05.002

Dewey, J. 2005. Art as experience. Westminster , UK: Penguin. 
Dritsas, A., Kaloghirou, A., \& Cokkinos, D.V. 2001. The effects of music on the exercise performance in cardiac patients: A clinical implication of brain-heart interaction. Paper presented at the Proceedings of the Spring Annual Meeting of the European Society of Cardiology, Working Group of Exercise Physiology and Cardiac Rehabilitation, Bergen, NO.

Fukugawa, N. 2006. Science parks in Japan and their value-added contributions to new technology-based firms. Interna- tional Journal of Industrial Organization, 24(2): 381-400. DOI: 10.1016/j.ijindorg.2005.07.005

Fullwood, R., Rowley, J., \& Delbridge, R. 2013. Knowledge sharing amongst academics in UK universities. Journal of Knowledge Management, 17(1): 123-136. DOI:10.1108/13673271311300831

Howells, J., Ramlogan, R., \& Cheng, S.L. 2012. Universities in an open innovation system: A UK perspective. International Journal of Entrepreneurial Behavior \& Research, 18(4): 440-456. DOI: 10.1108/13552551211239483

Högberg, C., \& Edvinsson, L. 1998. A design for futurizing knowledge networking. Journal of Knowledge Management, 2(2): 81-92. DOI: $10.1108 / 13673279810249404$

Johnston, L., Robinson, S., \& Lockett, N. 2010. Recognising "open innovation" in HEI-industry interaction for knowledge transfer and exchange. International Journal of Entrepreneurial Behavior \& Research, 16(6): 540-560.

DOI: $10.1108 / 13552551011082498$

Jer Yuen, T., \& Shaheen Majid, M. 2007. Knowledge-sharing patterns of undergraduate students in Singapore. Library Re- view, 56(6): 485-494. DOI: 10.1108/00242530710760382

Lee, S., Park, G., Yoon, B., \& Park, J. 2010. Open innovation in SMEs-An intermediated network model. Research Policy, 39(2): 290-300. DOI: 10.1016/j.respol.2009.12.009

Ma, W.W., \& Yuen, A.H. 2011. Understanding online knowledge sharing: An interpersonal relationship perspective. Computers \& Education, 56(1): 210-219. D0I: 10.1016/j.compedu.2010.08.004

Padilla-Meléndez, A., \& Garrido-Moreno, A. 2012. Open innovation in universities: What motivates researchers to engage in knowledge transfer exchanges? International Journal of Entrepreneurial Behavior \& Research, 18(4): 417-439.

DOI: $10.1108 / 13552551211239474$

Perkmann, M., \& Walsh, K. 2007. University-industry relationships and open innovation: Towards a research agenda.

In- ternational Journal of Management Reviews, 9(4): 259-280. D0I: 10.1111/j.1468-2370.2007.00225.x

Pham, A.T., Nguyen, N.T., \& Nguyen, D.M. 2015. Influence of organizational and technological aspects on the knowledge sharing behaviour in the Vietnam's University context. Asian Social Science, 11(10): 139-152.

Pan, S.L., \& Leidner, D.E. 2003. Bridging communities of practice with information technology in pursuit of global knowledge sharing. The Journal of Strategic Information Systems, 12(1): 71-88. D0I: 10.1016/S0963-8687(02)00023-9

Richard, F. 1999. Engine or infrastructure? The university role in economic development. Cambridge, MA: MIT Press.

Schartinger, D., Rammer, C., Fischer, M.M., \& Fröhlich, J. 2002. Knowledge interactions between universities and industry in Austria: Sectoral patterns and determinants. Research Policy, 31(3): 303-328. D0I: 10.1016/S0048-7333(01)00111-1 Tran, T. A., \& Kocaoglu, D.F. 2009. Literature review on technology transfer from government laboratories to industry. Paper presented at the Management of Engineering \& Te chnology, Portland, US. DOI: 10.1109/picmet.2009.5261800 Vygotsky, L. 1978. Interaction between learning and development. Readings on the Development of Children, 23(3): 34- 41.

Wang, S., \& Noe, R.A. 2010. Knowledge sharing: A review and directions for future research. Human Resource Management Review, 20(2): 115-131. DOI: 10.1016/j.hrmr.2009.10.001

Wei Chong, C., Yen Yu en, Y., \& Chew Gan, G. 2014. Knowledge sharing of academic staff: A comparison between private and public universities in Malaysia. Library Review, 63(3): 203-223. DOI: 10.1108/LR-08-2013-0109

Youtie, J., \& Shapira, P. 2008. Building an innovation hub: A case study of the transformation of university roles in regional technological and economic development. Research Policy, 37(8): 1188-1204. DOI: 10.1016/j.respol.2008.04.012

Zaqout, F., \& Abbas, M. 2012. Towards a model for understanding the influence of the factors that stimulate university students' engagement and performance in knowledge sharing. Library Review, 61(5): 345-361. DOI: 10.1108/0024253121 1280478 